\title{
Studi Komparasi Konsep Jubata dan YHWH dalam Keluaran 3:14 Sebagai Upaya Kontekstualisasi Berita Injil Bagi Suku Dayak Kanayatn
}

\author{
Andre Vinsensius David \\ Sekolah Tinggi Teologi Tawangmangu, Tawangmangu \\ vinsensiusdavid5@gmail.com \\ Firman Panjaitan \\ Sekolah Tinggi Teologi Tawangmangu, Tawangmangu \\ panjaitan.firman@gmail.com
}

\begin{abstract}
The church in Indonesia is still struggling with contextualization effort that are able to land the understanding of Biblical Theology into the understanding of the local community. This happened because the church's attitude tended to reject local wisdom and force western culture into the context of Indonesian Culture, especially the Kanayatn Dayak Culture. Several previous studies have tried to see how the Kanayatn Dayak tribe understand their faith in Jubata which is reflected in their local wisdom. However, these studied have no yet reach an attempt to estabilish Jubata's identity as Yahweh. Therefore this article seeks to show that Jubata is Yahweh who has previously revealed himself to Israel, to build a contextual theology capable of transforming culture and the church, using qualitative research methods of ethnographic studies to examine to the local wisdom of the Kanayatn Dayak tribe and Intepretation textual to see how Yahweh existed in Exodus 3:14. The values of chirst must renew the local wisdom of the Dayak Kanayatn tribe and Jubata must be understood not as idols but as Yahweh who has sovereignty over the universe in the local wisdom version Dayak Kanayatn tribe. Because Jubata is Yahweh who has revealed himself with the phrase "I AM THAT I AM" to declare His eternal and sovereign existence to reveal himself to all mandkind, especially Dayak Kanayatn tribe.
\end{abstract}

Keywords: Jubata, Dayak Kanayatn, Yahweh, Church, Contextualization

\begin{abstract}
Abstrak
Gereja di Indonesia masih bergumul dengan upaya kontekstualisasi yang mampu mendaratkan pemahaman Teologi Alkitabiah kepada pemahaman masyarakat lokal. Hal itu terjadi karena sikap gereja yang cenderung menolak kearifan lokal dan memaksa kebudayaan barat kedalam konteks budaya Indonesia, secara khusus budaya Dayak Kanayatn. Beberapa peneliatan sebelumnya telah mencoba untuk melihat bagaimana Suku Dayak Kanayatn memahami iman mereka kepada Jubata yang tergambar pada kearifan lokal yang mereka miliki. Akan tetapi penelitian-penelitian itu belum sampai kepada upaya menunjukkan identitas Jubata sebagai Yahweh. Oleh sebab itu artikel ini berupaya menunjukkan bahwa Jubata adalah Yahweh yang dahulu telah menyatakan diri-Nya pada Israel, untuk membangun sebuah teologi yang kontekstual sehingga mampu mentransformasi budaya dan gereja, dengan menggunakan metode penelitian kualitatif studi etnografi untuk meneliti kearifan lokal suku Dayak Kanayatn dan tafsir tekstual untuk melihat bagaimana eksistensi
\end{abstract}


Yahweh dalam keluaran 3:14. Nilai-nilai Kristus harus memberi kebaharuan pada kearifan lokal suku Dayak Kanayatn dan Jubata harus dipahami bukan sebagai berhala namun sebagai Yahweh yang berdaulat atas alam semesta dalam versi kearifan lokal suku Dayak Kanayatn. Sebab Jubata adalah yang Yahweh telah menyatakan diri-Nya dengan ungkapan "AKU ADALAH AKU ADA" untuk menyatakan eksistensi-Nya yang kekal dan berdaulat untuk menyatakan diri-Nya pada seluruh umat manusia, secara khusus suku Dayak Kanayatn.

Kata Kunci: Jubata, Dayak Kanayatn, Yahweh, Gereja, Kontekstualisasi

\section{PENDAHULUAN}

Pergumulan gereja-gereja di Indonesia dalam pekabaran Injil masih bergelut dalam upaya kontekstualisasi. Gereja dengan kiblat teologi Barat dan kebudayaan modern, kurang dapat menerima sistem kebudayaan dan kepercayaan lokal. Hal ini yang mengakibatkan pemberitaan Injil kurang maksimal serta tidak mendapatkan tempat dalam kebudayaan. Hal ini juga yang terjadi dalam upaya pekabaran Injil di tanah Borneo, khususnya pada suku Dayak Kanayatn. Menurut suku Dayak Kanayatn, kekristenan adalah agama asing yang hidup di tengah mereka. Tanpa upaya kontekstual yang baik, tentunya kekristenan bukanlah hal yang mudah untuk diterima sebagai sebuah kepercayaan atau agama, karena adat dan budaya sudah menjadi darah daging yang tak dapat dilepaskan dari kehidupan.

Berkaitan dengan hubungan antara Injil dan kebudayaan, Richard Niebuhr melihat lima sikap gereja terhadap kebudayaan yang cenderung menjadi cara pandang gereja terhadap budaya ${ }^{1}$ yakni, pertama, Kristus melawan kebudayaan, dimana gereja merasa tidak perlu berkompromi dengan budaya yang tidak sesuai dengan Kristus. Kedua, Kristus dari kebudayaan menganggap bahwa kebudayaan ditafsirkan melalui Kristus dan Kristus dipahami melalui kebudayaan (mengkombinasikan Kristus dan kebudayaan) Ketiga, Kristus diatas kebudayaan menganggap bahwa Kristus Anak Allah yang menciptakan alam semesta juga menciptakan budaya. Keempat, Kristus dan kebudayaan dalam paradoks menganggap bahwa manusia sering diperhadapkan dengan dualisme yang paradoks dimana kebudayaan manusia cenderung membawa pada dosa, tetapi anugerah Allah mengampuni dosa manusia. Terakhir, kelima, Kristus mentransformasi kebudayaan menganggap bahwa Kristus sebagai pengubah/pembaharu sebuah kebudayaan.

Penulis memandang bahwa sikap yang paling ideal untuk diterapkan dalam

${ }^{1}$ Richard Niebuhr, Christ And Culture (New York: Herper And Row Publisher, 1951). 
konteks gereja di suku Dayak Kanayatn adalah gereja mentransformasi kebudayaan; bukan melawan kebudayaan dengan alasan bahwa kebudayaan dan kearifan lokal suku Dayak Kanayatn adalah identitas yang tidak boleh dihilangkan dari setiap orang Dayak Kanayatn yang menjadi Kristen. ${ }^{2}$ Selain itu, kearifan lokal suku Dayak Kanayatn tidak boleh dipandang sebagai ancaman sinkretisme bagi gereja; melainkan sebuah peluang untuk memasukkan nilainilai Injil yang mampu mentransformasi nilai dalam kebudayaan suku Dayak Kanayatn. Salah satu yang perlu ditransformasi oleh gereja adalah nilai dan muatan teologis kepercayaan suku Dayak Kanayatn terhadap pemahaman tentang Jubata yang dianggap sebagai pencipta alam semesta. Keyakinan itu perlu dibaharui dan diarahkan kepada Tuhan (Yahweh atau Yesus) sebagai pencipta alam semesta. Hal ini sependapat dengan pendapat Mawene bahwa gereja tidak perlu memandang negatif sebuah kebudayaan lokal ${ }^{3}$, tetapi gereja perlu melihat peluang untuk memasukkan Injil ke dalam kebudayaan

\footnotetext{
2 Firman Panjaitan, "Membangun Teologi Pertanian Melalui Pembacaan Lintas Tekstual Injil Matius Dan Kosmologi Jawa," Bonafide: Jurnal Teologi dan Pendidikan Kristen 1, no. 1 (2020): 44-64.

3 Mathinus Theodorus Mawene, Perjanjian Lama Dan Teologi Kontekstual (Jakarta: BPK Gunung Mulia, 2017), 3.
}

tersebut dan memperbaharui nilai dalam kebudayaan dengan Kristus.

Nilai-nilai Kristen harus dapat memberi kebaharuan kepada kearifan lokal suku Dayak dan Jubata harus dipandang bukan sebagai sebuah berhala melainkan sebagai Yahweh dalam versi kearifan lokal Dayak Kanayatn, sehingga nilai luhur dan identitas suku Dayak Kanayatn tidak ditinggalkan dan diganti dengan kebudayaan asing. Oleh sebab itu artikel ini bertujuan untuk membangun sebuah teologi yang kontekstual atau cocok dengan pemahaman kebudayaan Dayak Kanayatn tentang Tuhan sebagai sarana menjelaskan nilai-nilai dalam Kristus kepada masyarakat adat sekaligus membuka wawasan gereja lokal untuk dapat menerima kearifan lokal sebagai warisan budaya yang tidak boleh ditinggalkan.

Untuk membatasi pembahasan yang melebar, penelitian dalam artikel ini hanya mencakup bagaimana konsep Jubata dalam budaya dan kepercayaan suku Dayak Kanayatn dari sudut pandang etnografi dan bagaimana eksistensi Yahweh dalam Keluaran 3:14.

\section{METODE PENELITIAN}

Dalam penulisan artikel ini penulis menggunakan metode kualitatif 
khususnya pendekatan literature research. ${ }^{4}$ Penelitian kualitatif adalah riset yang bersifat deskriptif dan cenderung menggunakan analisis induktif, yang menonjolkan proses penelitian dan pemanfaatan landasan teori dengan tujuan agar penelitian sesuai dengan fakta lapangan. Selain itu, landasan teori juga bermanfaat untuk memberikan gambaran umum tentang latar belakang penelitian dan sebagai bahan pembahasan dan hasil penelitian. Penelitian kualitatif disebut juga dengan interpretative research, yang menekankan makna, penalaran, definisi dan situasi tertentu, serta lebih banyak meneliti tentang masalah yang biasa terjadi sehari-hari. Pendekatan kualitatif lebih mementingkan proses dari pada hasil akhir. Oleh karena itu urutan penelitian dapat berubah-ubah bergantung pada kondisi dan banyaknya gejala-gejala temuan. Tujuan utama yang menggunakan pendekatan kualitatif adalah mengembangkan pengertian, konsep-konsep yang pada akhirnya menjadi teori. Tahap ini dikenal dengan grounded theory research..$^{5}$ Model penelitian kualitatif yang penulis gunakan dalam penelitian ini adalah studi pustaka

4 Mestika Zed, Metode Penelitian Kepustakaan, 3rd ed. (Jakarta: Yayasan Pustaka Obor Indonesia, 2014), 1-2.

${ }^{5}$ Rukin, Metode Penelitian Kualitatif, 1st ed. (Takalar: Yayasan Ahmar Cendikia Indonesia, 2019), 6 . yang mengumpulkan data terkait masalah, landasan teori dan isi dalam pembahasan dari berbagai sumber literatur kepustakaan yang mendukung pembahasan. ${ }^{6}$

Untuk meneliti konsep Jubata dalam pemahaman suku Dayak Kanayatn penulis menggunakan studi etnografi, khususnya dengan langkah Thick Description (deskripsi tebal atau melukis dengan dalam) yang meneliti dan menguraikan kebudayaan, kepercayaan, kebiasaan-kebiasaan suku Dayak Kanayatn. Langkah ini tidak sekadar wawancara bersama tokoh-tokoh adat Dayak Kanayatn, namun juga hidup dan menjadi bagian dalam kebudayaan itu. Penelitian ini juga didukung dengan sumber-sumber literature kepustakaan yang memuat kajian-kajian tentang kebudayaan dan kepercayaan suku Dayak Kanayatn. $^{7}$

Langkah-langkah yang penulis lakukan dalam pendekatan ini adalah mengamati fenomena lapangan berkaitan dengan keyakinan suku Dayak Kanayatn terhadap Jubata sebagai pencipta alam semesta. Hasil pengamatan itu kemudian dijadikan sebuah gambaran abstrak tentang konsep Jubata sebagai pencipta. Kemudian penulis menghubungi

${ }^{6} \mathrm{Zed}$, Metode Penelitian Kepustakaan.

7 Clifford Geertz, "The Interpretation Of Cultures (Basic Books Classics)" (1977): 6. 
beberapa tokoh adat yang dapat dijadikan narasumber dalam pelaksanaan wawancara. Penulis memilih lima narasumber yang mewakili temenggung adat, juru kunci gunung, pelaku okultisme dan pegiat seni dan budaya Dayak Kanayatn. Dari keterangan yang mereka berikan, penulis membandingkannya dengan hasil pengamatan lapangan dan dengan sumber-sumber literature yang menulis informasi terkait budaya Dayak Kanayatn, terkhusus konsep tentang Jubata. Hasil penelitian kemudian dimuat dalam bentuk naratif-deskriptif di dalam jurnal.

Untuk meneliti Yahweh dalam Keluaran 3:14 penulis menggunakan pendekatan kritik tekstual yang berusaha menjangkau teks asli dengan mengadakan konstruksi teks yang terjadi pada masa teks itu ditulis, yang diterima sebagai kitab sebelum pengkanonan seluruh Alkitab. Dengan pendekatan ini, peneliti dapat mempelajari dan mampu mengenali kesalahan-kesalahannya untuk dibenarkan; bagaimana penulis dapat melengkapi, menyisipkan dan memelihara sampai pada penulisan yang kurang atau berlebihan. ${ }^{8}$

\section{HASIL DAN PEMBAHASAN}

\section{Sejarah Suku Dayak Kanayatn}

Suku Dayak Kanayatn merupakan satu dari 405 sub suku Dayak yang tersebar di seluruh pulau Kalimantan. ${ }^{9}$ Suku Dayak meliputi beberapa sub diantaranya Dayak Ahe, Banyadu, Bakati, Belangin, yang tersebar di beberapa kabupaten diantaranya Pontianak (sekarang Kabupaten Mempawah), Bengkayang, Landak dan Sambas. ${ }^{10}$ Dalam hal kebudayaan, suku Dayak Kanayatn tidak jauh berbeda dengan suku-suku Dayak lainnya. Percaya pada kekuatan supranatural (animisme dan dinamisme), hidup sebagai suku yang agraris-nomaden ${ }^{11}$, dan sangat menghargai serta menjunjung tinggi nilai adat dan budaya yang dipegang oleh kelompok masyarakat.

Redaksi BPK Gunung Mulia, 21st ed. (Jakarta: BPK Gunung Mulia, 2016), 36.

9 Hamid Darmadi, "Dayak Asal-Usul Dan Penyebarannya Di Bumi Borneo," Sosial Horizon 3, no. 2 (2016): 322-340.

$$
10 \text { Ibid. }
$$

11 Sebelum kemajuan teknologi dan industry masuk ke wilayah Kalimantan Barat, pertanian masih dilakukan nomaden dengan cara membuka lahan baru setiap tahunnya. Setelah kemajuan teknologi dirasakan masyarakat, pertanian sekarang lebih menetap di satu daerah dengan memanfaatkan fasilitas teknologi yang di sediakan pemerintah. Mereka juga harus memilih agama yang diakui negara untuk legalitas pencatatan sipil. 
Hal yang membedakan budaya Kanayatn dengan Dayak yang lain adalah tradisi Naik Dango. Naik Dango adalah tradisi untuk menghormati atau mengucap syukur kepada Tuhan alam semesta yang dikenal dengan sebutan Jubata yang sudah memberkati setiap jerih payah dalam pertanian (terutama padi). Penghargaan dan penghormatan itu diwujudkan dalam sebuah tradisi pesta panen padi yang diselenggarakan serentak di wilayah-wilayah yang berbeda. ${ }^{12}$

\section{Awalnya $^{13}$, tradisi Naik Dango} biasanya dilaksanakan pada 27 April-31 Mei (sesuai kesepakatan musyawarah daerah) dari masing-masing rumah warga yang ingin mengucap syukur sekaligus memohon berkat kepada Jubata untuk tahun berikutnya. Pesta ini dengan mengundang tetua adat untuk berdoa dan siapa saja yang mau datang ke rumah mereka untuk menikmati hidangan bersama. Namun tradisi ini mengalami sedikit pergeseran makna ketika tanah Dayak dianggap terkutuk dan tidak mampu menghasilkan hasil bumi secara

12 Jubata adalah Tuhan dalam Bahasa Dayak Kanayatn. Dalam penjelasan Paiman dan Herkulanus Ahar, Jubata telah menciptakan dunia dengan segala isinya termasuk manusia. Bagi Jubata, manusia adalah gambar dan rupa-Nya yang Ia pelihara di bumi. Pemeliharaan-Nya ia buktikan dengan memberkati segala jerih payah yang dilakukan oleh manusia.

${ }^{13}$ Heridawati, "Naik Dango: Ucapan Syukur Dalam Menghormati Padi Pada Suku Dayak Kanayatn 1985-1991,” 2007. maksimal (1968-1980) akibat konflik pertumpahan darah dengan etnis Tionghoa pada tahun 1967 karena menganggap seluruh etnis Tionghoa merupakan sekutu PKI dan PGRS Paraku $^{14}$ yang berusaha memecah belah kedaulatan NKRI dan keamanan masyarakat Dayak.

Menanggapi masalah ini, tokohtokoh adat Dayak bermufakat bersama Oevang Oeray untuk menumpas gerakan separatis tersebut. Penumpasan tersebut berakhir dengan pertumpahan darah dan pengusiran etnis China yang berada di pedalaman untuk pergi dari sana. Peristiwa inilah yang masih dikenal hingga sekarang dengan sebutan mangkok merah.

Akibat pertumpahan darah ini tanah Kalimantan, secara khusus Kalimantan Barat mengalami kesulitan panen. Menurut keyakinan masyarakat Dayak Kanayatn hal itu diakibatkan oleh tanah yang sudah kotor akibat partumpahan darah yang terjadi. Pertumpahan darah itu kemungkinan telah menimbulkan amarah Jubata kepada masyarakat Dayak.

Jubata sebagai pelindung dan pemelihara yang berdaulat atas kehidupan mereka menjadi marah dengan perbuatan orang Dayak yang

14 Superman Superman, "Peristiwa Mangkok Merah Di Kalimantan Barat Tahun 1967," Historia 5, no. 1 (2017): 1. 
menghilangkan nyawa sesama manusia tanpa belas kasihan. Menyadari hal tersebut, dewan-dewan adat bermufakat untuk memohon ampun sekaligus meminta Jubata untuk menguasai tanah ai' karamat (tanah air dan keramat) melalui tradisi naik dango. Sesuai kesepakatan, acara Naik dango dilakukan secara terorganisir dan komunal ditempat-tempat yang dianggap memakan korban paling banyak dengan fokus tujuan memohon ampun dan memohon berkat (1985-1991).

Memasuki tahun 1992 tradisi ini tidak lagi dilakukan di tempat yang paling banyak membunuh orang China, tetapi di kecamatan yang memiliki rumah adat dan dianggap mampu menyelenggarakan tradisi ini. Sekarang ini tradisi ini tidak hanya dimaknai sebagai ungkapan permohonan dan ucapan syukur, tetapi juga mengandung nilai persahabatan dan kekeluargaan (karena dilakukan secara bersama-sama dalam jumlah kelompok yang besar), baik itu sesama suku Dayak maupun etnis lain yang juga hadir untuk memeriahkan acara Naik Dango sebagai wujud kasih dan perdamaian sesama manusia.

\section{Sistem Keyakinan dalam Hukum Adat dan Tradisi Dayak Kanayatn}

Orang Dayak Kanayatn meyakini bahwa seluruh elemen dalam kehidupan telah diatur oleh Jubata (dalam doa orang Dayak Kanayatn dikenal dengan nama Nek Sapati), termasuk hukum adat, tradisi dan budaya. Semua hukum itu telah di wahyukan kepada generasi terdahulu dan diturunkan kepada generasi berikutnya melalui tradisi lisan. Secara khusus, hukum dijalankan secara terorganisir oleh struktural tetua adat ${ }^{15}$ yang telah terpilih berdasarkan kekuatan, kecerdikan, wibawa yang mereka miliki, di wilayahwilayah yang mereka pimpin. Secara operasional akan sangat luas sekali untuk membahas sistem hukum Dayak Kanayatn. Tetapi dalam pemahaman yang sedikit sempit hukum $^{16}$ adat berfungsi untuk menata atau mengatur sikap etis setiap warga desa atau daerah serta menjadi media untuk menengahi konflik internal atau konflik eksternal yang berkaitan dengan warga kampung yang berkaitan. ${ }^{17}$ Selain mengatur sikap

${ }^{15}$ Fridolin Ukur, Tantang-Jawab Suku Dayak, 1st ed. (jakarta: Balai Penerbit Kristen, 1971), 78 .

16 RAONIGEL TALU MARAGA, "Penyelesaian Sengketa Kepemilikan Tanah Di Lingkungan Masyarakat Adat Dayak Kanayatn, Kecamatan Menyuke, Kabupaten Landak, Provinsi Kalimantan Barat," Universitas Diponegoro Semarang (Universitas Diponegoro Semarang, 2017).

17 Denny Satria, "Penerapan Hukum Adat Daya' Kanayatn Dalam Penyelesaian Kasus Hukum Pidana Di Kabupaten Landak Dan Dasar 
etis terhadap sesama masyarakat, hukum dan tradisi juga mengatur sikap etis hubungan antara manusia dengan alam agar tetap terjaga kelestariannya ${ }^{18}$ mengingat bahwa masyarakat Dayak Kanayatn adalah masyarakat yang agraris; juga mengatur sikap etis antara manusia dengan alam supranatural dengan maksud menjaga penghormatan pada Jubata dan arwah nenek moyangnya ${ }^{19}$.

Karena hal itulah Nek Sapati selalu mendapat tempat untuk dimintai restu, berkat, pengampunan, petunjuk dalam setiap ungkapan doa (tetua adat) suku Dayak Kanayatn karena Ia memegang kedudukan tertinggi sekaligus yang menurunkan hukum adat untuk dihidupi oleh manusia. Tanpa restu dari Nek Sapati, semua kebijakan dan keputusan yang diambil dikhawatirkan akan membawa petaka yang berakibat fatal terhadap kehidupan masyarakat suku Dayak Kanayatn.

\section{Kebudayaan Tradisi Lisan Suku Dayak Kanayatn}

Tradisi lisan merupakan ungkapan ekspresi-mental warga suatu kebudayaan

Pemikiran Pengaturannya Ke Dalam Peraturan Daerah," n.d.

18 Darmadi, "Dayak Asal-Usul Dan Penyebarannya Di Bumi Borneo."

19 Hartatik, Adat Dan Perubahan Budaya Pada Masyarakat Suku Dayak Kanayatn, 2016, 87-102. yang dimiliki secara kolektif dan diturunkan dari generasi ke generasi melalui tradisi lisan dalam kebudayaan suku Dayak Kanayatn. Sebagai warisan yang kolektif, tradisi lisan wariskan secara menyebar dan tradisional dalam versi yang berbeda, biasanya disertai dengan gerak, mimik bahkan benda sebagai alat bantu untuk mengingat. Fungsinya sebagai sarana informasi, penyaksian, dan kebiasaan lisan. Ketiganya digunakan dalam kegiatan sehari-hari seperti di ladang, di hutan, dan tentu saja di rumah.

Berdasarkan pengamatan Ukur ${ }^{20}$, menurut riwayat yang dituturkan oleh masyarakat Dayak, sang Maha Kuasa telah menghimpun semua suku bangsa dan memberikan kitab suci-Nya kepada semua suku bangsa berdasarkan bahasa mereka masing-masing. Golongangolongan lain yang menerima kitab-kitab tersebut memelihara kitab tersebut hingga sekarang. Sedangkan orang Dayak yang harus kembali ke tempat asal mereka dengan melewati gunung dan lembah, laut dan sungai, berpikir demi menjaga keutuhan pesan dalam kitab tersebut, maka mereka menelan kitab suci tersebut secara bulat-bulat. Karena hal inilah kitab seluruh pesan dalam kitab suci tersebut dapat dikuasai dan dihafal dengan selengkapnya. dalam pemberitaannya, isi 
kitab suci tersebut dikisahkan secara verbal melalui tradisi lisan.

Dalam budaya Dayak, secara khusus Dayak Kanayatn terdapat banyak sekali bentuk-bentuk tradisi lisan yang memuat hiburan, pengetahuan, nasihat bijak, doa dan pandangan teologis didalamnya. Salah satu bentuk tradisi lisan yang akrab dijumpai adalah basingara atau dikenal dengan bercerita. $^{21}$ basingara biasanya berisi tentang kisah jenaka (kisah hewan), kisah heroic (kisah pahlawan terdahulu), hikayat (peristiwa yang memiliki pesan moral yang dalam), dan kisah religi (berisi pemahaman teologis terhadap Jubata).

Dengan demikian tradisi lisan, khususnya Singara mau menggambarkan keterkaitan hubungan kehidupan manusia di dalam alam semesta dan peran penting Jubata sebagai Tuhan dalam keyakinan mereka yang memegang kedaulatan atas alam semesta. Di dalam singara dapat dijumpai informasi-informasi yang menggambarkan bagaimana orang Dayak Kanayatn memahami Jubata dan karyakarya Jubata dalam kehidupan manusia.

21 Dwi Oktaviani Ursula, "Mantra Upacara Ngabati' Pada Upacara Pertanian Suku Dayak Kanayatn Di Dusun Pakbuis Desa Banying Kecamatan Sengah Temila Kabupaten Landak Kalimantan Barat," Vox Edukasi (2015).
Dalam pandangan suku Dayak Kanayatn, dunia dengan segala isinya diciptakan oleh Jubata ${ }^{22}$ yang bersifat kekal dan tunggal (dalam hakikatnya sebagai Tuhan) namun dapat disapa dengan banyak sebutan. Sapaan yang terkenal dalam kisah penciptaan itu antara lain Jubata sapati (Yang Maha Kuasa) Pangira (sang pengira/memperkirakan), Pangedokng (sang Penata), Pajaji (yang menjadikan segala sesuatu), Panampa (pembentuk manusia yang seperti kita), Panange (yang membentuk rupa manusia sejak dalam kandungan). Nama-nama ini yang mewakili sifat-sifat Jubata yang dikenal suku Dayak Kanayatn; diyakini bahwa sebelum dunia diciptakan, pernah terjadi kiamat ketiga ${ }^{23}$ yang melenyapkan alam semesta. Oleh sebab itu bumi dan segala isinya diciptakan kembali. Sebelum dunia diciptakan, Jubata memperkirakan dengan matang bagaimana dunia harus dibentuk. Perkiraan tersebut kemudian mulai dirancang/ditata satu-persatu tentang tata letak semua unsur yang akan diciptakan. Kemudian barulah semua ciptaan diciptakan. Tumbuhan, hewan dan semua unsur dalam alam semesta

22 Wawancara virtual bersama Paiman 11 Agustus 2020 dan Herkulanus Ahar pada 10 Agustus 2020 dan Imor pada 13 Agustus 2020.

23 Tidak ada keterangan tentang kiamat pertama dan kedua. 
menempati posisi yang telah ditentukan. Dalam proses penciptaan dunia diperkirakan selama tujuh hari, karena angka tujuh merupakan angka yang sakral bagi suku Dayak Kanayatn. Setelah semuanya selesai kemudian seluruh ciptaan dinilai ulang dan Jubata memandangnya sangat baik adanya.

Manusia diciptakan oleh Jubata panampa dari tanah Malae yang diambil dari Pauh Janji Pusat Ai' oleh burung merpati. Kemudian dari tanah itu mulai dibentuk sebuah model yang disebut sebagai manusia. Akan tetapi bentuk menusia tersebut menyerupai kera. Dalam penilaian Jubata Pangedokng bentuk tersebut belum sempurna karena berbentuk kera; bukan manusia.

Kemudian penciptaan tersebut diulangi kembali dengan tanah yang diambil oleh burung merpati dari Pauh Janji Pusat Ai' sampai akhirnya terbentuk sebuah model manusia yang sempurna dalam pandangan Jubata. Kemudian manusia itu ditempatkan pada sebuah rumah yang untuk didiami. Jubata Panange sangat memberkati manusia itu dengan banyak anak yang lahir dari rahimnya, sehingga rumah manusia pertama itu tidak dapat menampung anak-anak dan cucu mereka yang tinggal bersama mereka. Akhirnya rubuhlah rumah itu dan mengakibatkan anak-anak dan cucu-cucunya berpencar ke berbagai daerah, sehingga manusia tidak lagi menjadi satu rumpun. Itulah sebabnya ada suku Melayu, Jawa, Tionghoa, dan lainnya dimuka bumi ini.

Itulah kisah tentang penciptaan alam semesta dalam versi suku Dayak Kanayatn. Kisah ini memiliki muatan teologis yang masih dipegang hingga masa kini. Jubata dalam pemahaman mereka inilah yang mengatur seluruh aspek dalam kehidupan manusia termasuk hukum adat dan pertanian yang menjadi hal penting bagi suku Dayak Kanayatn. Sebagaimana Jubata dahulu telah berkarya dalam kehidupan manusia, demikian juga dipercaya bahwa Jubata masih berkarya dan akan selalu berkarya dalam kehidupan manusia.

\section{Analisis tekstual Keluaran 3:14}

Konteks Keluaran 3 Secara Umum

Keluaran 3 adalah bagian dari rangkaian peristiwa keluarnya Israel, yang didahului dengan kisah penindasan Israel di Mesir (Kel. 1) pembantaian anak laki-laki Israel dan penyelamatan Musa (Kel. 2), pengutusan Musa (Kel. 2) dan kisah perjumpaan pertama Musa dengan Yahweh di gunung Horeb (Kel. 3). Dalam perjumpaan tersebut Allah menyatakan diri-Nya dengan memperkenalkan diri-Nya sebagai Allah nenek moyang Israel (Kel.3:6) sekaligus ingin meyakinkan Israel melalui Musa 
bahwa Dia adalah "yang selalu ada" bahkan ketika Israel sedang tertindas (Kel.3:14). Dengan perkenalan itu Allah ingin membawa Israel keluar dari Mesir untuk membebaskan mereka dari perbudakan dan kembali ke tanah Kanaan yang dahulu dijanjikan kepada Abraham, nenek moyang mereka. Peristiwa inilah yang menjadi pokok kepercayaan Israel atau boleh dikatakan sebagai pokok teologi yang mereka pegang. ${ }^{24}$

\section{Ungkapan "AKU ADALAH} AKU" (keluaran 3:14) menjadi perhatian yang menarik dalam Keluaran pasal 3. Seringkali ungkapan ini hanya diartikan sebatas nama yang dimiliki oleh Tuhan. dalam arti yang sempit, pada bagian ini Allah hanya memperkenalkan nama-Nya saja supaya mudah untuk dikenal atau disebut. Akan tetapi ungkapan ini tidaklah sesempit yang dimaksudkan kebanyakan orang. Ungkapan "AKU ADALAH AKU" menyiratkan sebuah makna eksistensi Allah yang sedang bertemu dan mengutus Musa.

Untuk menanyakan nama seseorang dalam budaya Ibrani biasanya menggunakan kata $m i^{25}$ (siapakah), namun dalam pertanyaan Musa tentang

${ }^{24}$ Christoph Barth and Marie-Claire Barth, Teologi Perjanjian Lama 1, ed. Borozatulo Gea and Chrisostomus Sihotang, 1st ed. (Jakarta: BPK Gunung Mulia, 2008), 118-119.

${ }^{25}$ Bambang Noorsena, The History of Allah, 6th ed. (Yogyakarta: Andi, 2010), 16. identitas Allah, Musa menggunakan kata mah (bagaimana) tentang nama-Nya (Kel.3:13). Seperti yang kutip Kaiser, Menurut Marthin Buber ${ }^{26}$ menjelaskan kata mah (apakah/bagaimanakah) dalam Frasa "apakah/bagaimanakah (nama) yang harus kukatakan" (kel. 3:13) berbeda arti dengan kata siapa $(M i)$. kata 'siapa' hanya menunjukkan kepada seseorang, sedangkan kata mah jika dikaitkan dengan nama akan merujuk kepada kualitas, karakter, kekuatan, kemampuan-kemampuan yang terkandung dalam nama tersebut. Musa berupaya untuk memperoleh jawaban yang jauh dan mendalam tentang arti dari nama dari sosok yang menyatakan Diri pada Musa, agar musa dapat memberi kepastian pada Israel tentang identitas dan otoritas sang pengutus Musa.

Secara umum terdapat dua teori tentang frasa "Ehyeh Asyer Ehyeh". Teori pertama adalah pandangan yang melihat frasa "Ehyeh Asyer Ehyeh" dari sudut pandang filologi atau etimologinya. Secara etimologi, kata ini memiliki kasus Hifil (kausatif), dimana frasa "Ehyeh Asyer Ehyeh" berfokus pada subjek (Yahweh) menjadi penyebab segala yang Ada. Argumen ini didasarkan pada parallel sumber ekstra-biblikal yakni

26 Walter C. Kaiser, Teologi Perjanjian Lama, 3rd ed. (Jakarta: BPK Gunung Mulia, 2013), 145. 
pandangan Mesir, Babilonia, Kanaan dan inskripsi Fenisi dari Karetepe ${ }^{27}$ Sehingga frasa "Aku Adalah Aku" tidak diterjemahkan "Ehyeh Asyer Ehyeh", namun diterjemahkan "Ehyeh Asyer Yihyeh" sehinga frasa tersebut berarti "Akulah Pencipta". Pandangan ini diikuti oleh Mangililo, Freedman, Haupt, dan Driver. $^{28}$

Namun pandangan tersebut dibantah oleh pandangan kedua yang melihat frasa "Ehyeh Asyer Ehyeh" dari sudut pandang Religio-historikal. Bila melihat kedalam terjemahan BHS yang mengikuti Masoret Teks dan LXX, kata kerja "Ehyeh" memiliki kasus Qal Imperfect aktif, ${ }^{29}$ dimana Masoret Text mengikuti rujukan dari $\mathrm{LXX}^{30}$ yang tetap

\begin{tabular}{l}
\hline 27 Eben Munthe, "Implikasi \\
Penggunaan \\
Kekristenan Masa Kini," 'YHWH' KURIOS
\end{tabular}
Yahweh: Suatu Tinjauan Etimologis Terhadap Arti Dan Penggunaan Nama Yahweh Berdasarkan Keluaran 3:14," Waskita, Jurnal Studi Agama dan Masyarakat Vol. III, No. 2, Nov. 2016: 161-176 (2016): 6.

${ }^{29}$ Bila memerhatikan keterangan pada footnote yang diberikan oleh BHS, maka frasa "Ehyeh Aster Ehyeh" mengikuti LXX yang menerjemahkannya dengan "ego eimi o wn" Kettel, ed., Biblica Hebraica Stuttgartensia, 1st ed. (New York: J.C. Hinrich, n.d.).

30 Penerjemahan Pentateukh dari naskah Ibrani ke bahasa Yunani (Koine) oleh tujuh puluh tua-tua Yahudi di kota Alexandria, Mesir pada masa pemerintahan Ptolemaus II Filadelfos abad ke-3 sM dengan tujuan melengkapi sumber litaratur kepustakaan Mesir dan kebutuhan orang Yahudi yang tidak bisa berbahasa Ibrani. terjemahan ini telah diakui keabsahannya dan kredibilitasnya, karena dianggap sangat mendekati dengan naskah Laut berfokus pada predikatnya (kata kerja) yakni "Ada". Bila diterjemahkan, frasa "Ehyeh Asyer Ehyeh" dalam BHS (MT) dan LXX berarti "Aku Adalah Aku Ada (menjadi, hadir)". Lebih dalam lagi Bagster dalam buku The Analitycal Hebrew And Chaldee ${ }^{31}$ menjelaskan kata "Ehyeh" tidak sekedar memiliki keterangan kasus qal imperfect saja, namun memiliki kasus qal future $1^{\text {st }}$ singular. Bila keterangan yang diberikan BHS, LXX dan Bagster digabungkan, maka frasa "Ehyeh Asyer Ehyeh" yang menerangkan bahwa Yahweh memiliki kontinuitas yang ada dan akan selalu ada.

Dari keterangan inilah penafsir modern seperti Bagster, Christoph Barth, Marie Claire Barth, George W. Coats, Elmer E. Towns, R. Clover, Goerge W. Knight, Jasper Klapwijk ${ }^{32}$ mengartikan bahwa Yahweh adalah Allah yang selalu hadir namun juga adalah pencipta, bertolak dari keterangan 'hayah' yang berarti 'ada' atau 'hidup'. Karena kata

Mati dan naskah Qumran. Bandingkan dengan Brando V Kondoj, "Mencari Jejak-Jejak Autograf Perjanjian Lama Di Dalam Septuaginta" (n.d.): 33-46.

31 Samuel Bagster And Son, The Analytical Hebrew And Chaldee Lexicon (London: Hendrickson Publisher, 1981), x.

32 Elmer E. Towns, Nama-Nama Allah, 7th ed. (Yogyakarta: Andi, 2008); R. Clover, The Sacred Name, 3rd ed. (USA: Qadesh La YAHWEH Press, 2002), 38; George W. Knight, The Names Of God, 5th ed. (Yogyakarta: Andi, 2015), 2; Jasper Klapwijk, Kabar Baik Dari Perjanjian Lama (Jakarta: Yayasan Komunikasi Bina Kasih/OMF, 2015), 78-79; Son, The Analytical Hebrew And Chaldee Lexicon; Barth and Barth, Teologi Perjanjian Lama 1. 
"ehyeh" berbentuk prediaktif qal, maka "ehyeh" berarti "menjadikan ada", 'menghidupkan', atau 'menciptakan'.

Kedua teori ini sama-sama mengatakan bahwa Yahweh adalah pencipta atau yang menciptakan. Letak perbedaannya adalah Mangililo, Freedman, Haupt, dan Driver meninjaunya dari sudut pandang filologi kata 'Ehyeh', yang berfokus pada makna yang terkandung dalam etimologi dan subjek frasa (kausalitas) tersebut, serta tidak begitu memerhatikan bagaimana frasa tersebut terbentuk dalam tradisi Alkitab. Argumentasi Freedman bersaman Mangililo, Haupt, Albright dan Driver yang melihat ungkapan "Ehyeh Asyer Ehyeh" sebagai ungkapan Kausalitas (hifil) Yahweh telah dibantah oleh Brevard S. Child. Child mengatakan bahwa nama Yahweh memang berasal dari bahwa proto semit dalam bentuk hifil. Namun hifil disini lebih didasarkan pada paralel sumber ekstra-biblikal dan bukan dari tradisi kitab Ibrani. ${ }^{33}$

Sedangkan teori kedua yang diikuti oleh Bagster, Christoph Barth, Marie Claire Barth, George W. Coats, Elmer E. Towns, R. Clover, Goerge W. Knight, Jasper Klapwijk tetap berpegang pada Religio-historikal yang melihat

33 Marthin Steven Lumingkewas, El Dan Yahweh Allah Israel (Yogyakarta: Diandra Kreatif, n.d.), 77. terbentuknya frasa Ehyeh Asyer Ehyeh dari bagaimana tradisi kitab Ibrani mengatakannya.

Dari kedua teori diatas, penulis sependapat dengan teori yang kedua, yang berpegang pada Religio-historikal, sehingga Yahweh dipadang sebagaimana tradisi kitab Ibrani menjelaskannya.

Kata Ehyeh Asyer Ehyeh dalam King James Version diterjemahkan "I Am That I Am", Terjemahan New American Standard menggunakan "I Am Who I $A m$ ". Keduanya memiliki translasi yang sama dengan apa yang diterjemahkan Terjemahan Baru yakni “AKU ADALAH AKU'. Sebutan ini kurang tepat bila diterjemahkan demikian ${ }^{34}$, mengingat bahwa Yahweh sendiri telah menjelaskan eksistensi-Nya yang kekal dengan sebuah kata petunjuk “Ada.” Perkenalan Yahweh sangat unik, karena Frasa "Ehyeh Asyer Ehyeh" itu bukan kata benda, bukan juga menunjukkan kepada individu; melainkan sebuah kata kerja.

Yahweh menjelaskan keberadaanNya bukan dari nama sebuah benda atau istilah, tetapi dari pekerjaan-Nya (predikatif) yang manusia dapat lihat. Frasa ini terbentuk dengan diawali dan

${ }^{34}$ Inilah yang membuat pemahaman tentang eksistensi Yahweh dalam Alkitab Bahasa Inggris dan terjamahan lainnya mengalami pembiasan makna bahkan sulit untuk dimengerti. Bdg. Clover, The Sacred Name. 
diakhiri dengan kata Ehyeh (qal impefect $1^{\text {st }}$ common singular) yang berarti "Aku menciptakan (pencipta) yang umum dikenal; sudah, sedang dan masih akan berulang-ulang (menampakkan diri)". kata Asyer (particle relative) adalah konjungsi yang menghubungkan kedua kata tersebut. Frasa ini berkaitan dengan tiga aspek waktu: hayah "Ia telah ada (dapat pula diterjamahkan Hidup)", Howeh "ia Ada" dan Yihyeh "Ia akan Ada". Maksud dari ungkapan itu menjelaskan bahwa Yahweh akan selalu Ada/Kekal namun tidak berubah $^{35}$ sekaligus menunjukkan tentang identitas diri dan kuasa-Nya yang mampu mengatur alam secara adikodrati dan keikutsertaan Yahweh dalam seluruh aspek kehidupan umat Israel secara khusus.

Oleh karena itu maksud sifat kekal Yahweh lebih merupakan sebuah janji kehadiran yang dinamis (dalam bentuk kata kerja yang imperfect) dimana Allah telah menyatakan diri-Nya berulang-ulang pada leluhur Israel dan Israel sendiri (imanensi Allah). hal ini sejala dengan pendapat Walther Eichordt ${ }^{36}$ bahwa ungkapan "ADA SEJAK ADA" dalam pemahaman dinamis telah menjamin eksistensi-Nya

\footnotetext{
${ }^{35}$ Knight, The Names Of God.

${ }^{36}$ Walther Eichordt, Theology of The
} Old Testament, 2nd ed. (London: SCM, 1993), 40. yang kekal dan mahakuasa. Jadi seharusnya Ehyeh Asyer Ehyeh diterjemahkan "Yang Ada Sejak Ada (Akulah Yang Kekal)" atau "Aku adalah Aku Ada" atau dalam terjemahan yang sederhana bisa disebut dengan "Aku Yang Selalu Ada" karena disini Yahweh ingin menjelaskan pribadi melalui pekerjaan-Nya pada dunia bahwa Ia selalu Ada dari awal hingga akhir.

Merujuk pada makna eksistensiNya yang Kekal dan Maha Kuasa serta janji kehadiran-Nya, Dialah yang menciptakan alam semesta (Kejadian 2:4); dan yang telah memilih Bapa leluhur Israel (Kejadian 12:1; Keluaran 3:6); dan yang ada bersama dengan Israel (imanensi-Nya) dalam masa penindasan di Mesir dan yang berusaha membawa keluar Israel menuju ke tanah Kanaan (Keluaran 3:7-8). Dalam kemahaadaan itu, kedaulatan penuh Yahweh atas alam semesta dapat dilihat dari sifat identitas dan penyataan Diri yang Ia tunjukan. Hal itu terbukti ketika Ia memukul kalah orang Mesir dan dewa-dewanya dengan sepuluh tulah, Dialah yang memelihara Israel sepanjang masa, yang membebaskan Israel dari penjajahan di zaman hakim-hakim. Dialah yang mengutus nabi-nabi untuk mengingatkan Israel akan firman-Nya. Dialah yang membebaskan Israel dari pembuangan di Babel. Dialah yang membebaskan Israel 
dari ancaman pembantaian Haman.

Dialah yang bertindak membebaskan Israel kemudian memelihara mereka. dengan menunjukkan sifat identitas-Nya, Dia yang maha-ada dan maha-Kuasa adalah Allah yang imanen dengan umatNya. ${ }^{37}$

Kesimpulan dari pemaparan di atas adalah bahwa ungkapan "Ehyeh Asyer Ehyeh" harus dipahami sebagaimana tradisi kitab Ibrani menjelaskannya; tidak perlu dari pararel ekstra-biblikal, sebab hal itu akan membiaskan makna "Ehyeh Asyer Ehyeh" yang dijelaskan oleh kitab Ibrani. "Ehyeh Asyer Ehyeh" memberi arti bahwa Tuhan yang menjumpai dan mengutus Musa adalah adalah Allah Maha Kekal dan Maha Kuasa, yang bereksistensi dengan sendirinya sekaligus menunjukkan bahwa Ia adalah Allah yang imanen dengan umat-Nya ${ }^{38}$.

Eksistensi Yahweh sebagai yang kekal dan penyebab segala sesuatu dalam pandangan umum dikenal dengan istilah Causa Prima ${ }^{39}$, dimana Allah dipahami sebagai penyebab pertama dari perbuatan-Nya sendiri; penyebab tentang

${ }^{37}$ Samin H. Sitohang, Siapakah Nama Sang Pencipta (Bandung: Yayasan Kalam Hidup, 2003), 45.

38 Sitohang, Siapakah Nama Sang Pencipta.

39 P.J. Suwarno, Pancasila Budaya Bangsa Indonesia, 9th ed. (Yogyakarta: Kanisius, 2009), 85. segala sesuatu ${ }^{40}$ yang ada di alam semesta; yang kekal; tidak ada penyebab lain diluar Tuhan ${ }^{41}$ merupakan asal mula dan tujuan dari segala sesuatu; pada-Nya tergantung segala sesuatu; maha kuasa; tidak berubah; tidak terbatas; zat mutlak; tidak dapat tidak; pengatur alam semesta; wajib ditaati.

\section{Perbandingan Konsep Jubata dan Yahweh dalam Keluaran 3:14}

Beranjak dari pemahaman Causa Prima di mana Tuhan diyakini sebagai penyebab segala sesuatu dan tidak dipengaruhi oleh apapun dari luar diriNya serta bereksistensi kekal, Jubata dan Yahweh memiliki kesejajaran. Dalam pemahaman masyarakat Dayak Kanayatn, Jubata merupakan pencipta alam semesta termasuk manusia di dalamnya; serta yang berdaulat penuh atas alam semesta untuk mengatur, menghukum dan memberkati umat manusia. Demikian juga Yahweh adalah pencipta alam semesta (Kejadian 2:4) yang mengaturnya dalam kebebasan kehendak-Nya. Dalam janji-Nya yang selalu Ada sepanjang masa (Kel. 3:14)

Lama 1.

${ }^{40}$ Barth and Barth, Teologi Perjanjian

41 Albert Sujoko, Belajar Menjadi Manusia, 5th ed. (Yogyakarta: Kanisius, 2012), 40. 
yang telah ditunjukkan berulang-ulang pada Israel, hal itu tidak hanya sekedar dirasakan oleh orang Israel, namun eksistensi-Nya itu ternyata juga telah dirasakan oleh masyarakat Dayak Kanayatn melalui penyataan umum yang Yahweh nampakkan dalam kearifan lokal suku Dayak Kanayatn.

Berdaulat atas alam semesta

Penyataan Yahweh dalam kearifan lokal tersebut dapat dilihat dari bagaimana Yahweh telah memperkenalkan diri-Nya sebagai yang berdaulat mengatur alam semesta (Kel. 3:14) dan telah dihayati dalam kehidupan sehari-hari suku Dayak Kanayatn. Masyarakat suku Dayak Kanayatn selalu meminta perlindungan, petunjuk dan memohon berkat serta berhati-hati menjaga etika agar senantiasa diberkati dan dilindungi Jubata sebagai Allah tertinggi. Dalam janji kehadiran-Nya itu, Yahweh menjadi pemelihara yang imanen, penjaga dan pengatur bangsa Israel yang menjaminnya dalam perjanjian di Sinai yang diikat dengan hukum (Keluaran 20). Hal ini mirip dengan sifat Jubata dalam kerangka berpikir hukum adat Dayak Kanayatn, telah bertindak sebagai Tuhan yang memelihara, memberkati, menghukum, dan mendidik suku Dayak melalui hukum. Jubata sama dengan Yahweh telah mengatur semua tatanan kehidupan dengan adil dan teratur.

Memelihara Manusia dengan Tanah dan Hasil Alam

Maksud Yahweh membawa keluar bangsa Israel dari adalah memberikan tanah Kanaan (Keluaran 3:8). Tanah Kanaan memiliki arti sangat penting dan menjadi pokok kepercayaan Israel, karena tanah itu adalah tanda perjanjian Yahweh dan umat-Nya sekaligus menjadi sumber penghidupan bagi Israel ${ }^{42}$.

Hal inipun mirip dengan cara orang Dayak Kanayatn memahami tanah sebagai milik Jubata yang harus dikelola sebagai sumber mata pencaharian dengan penuh tanggung jawab. Hutan tidak untuk di eksploitasi sebab Jubata berdaulat penuh atasnya. Jubata dapat menjatuhkan hukuman berupa bencana pada umat manusia karena merusak alam. Itulah sebabnya setiap tahun selalu diadakan perayaan panen padi atau Naik Dango yang dimaksudkan untuk mengucap Syukur sekaligus memohon pemeliharaan dan perlindungan Jubata.

\section{Kehadiran yang Kekal}

${ }^{42}$ Israel harus mengelola tanah yang di anugerahkan Tuhan dengan tanggung jawab dan dimiliki bersama. bdg Christoph Barth and Merie Claire Barth, Teologi Perjanjian Lama 2, ed. Gabo Gea, 1st ed. (Jakarta: BPK Gunung Mulia, 2010), 28. 
Yahweh yang adalah Kekal dan tidak terbatas dahulu telah menciptakan alam semesta dan telah menyatakan diriNya secara khusus pada Israel melalui Musa. Tetapi kedinamisan eksistensi-Nya itu telah dirasakan oleh seluruh manusia dimuka bumi, secara khusus masyarakat Suku Dayak Kanayatn.

Dayak Kanayatn menamakan yang Maha Ada dengan panggilan Jubata. Hal itu dapat dilihat jelas dari paralelisme yang terungkap dalam Alkitab dalam menjelaskan eksistensi Yahweh dan pemahaman iman masyarakat suku Dayak Kanayatn kepada Jubata lewat pola kultus dan hukum serta tradisitradisi yang ada. Hal ini didukung dengan pandangan panenteisme ${ }^{43} \quad$ yang mengatakan bahwa segala sesuatu ada di dalam Tuhan. Memang benar bahwa segala sesuatu berada dalam kedinamisan Yahweh termasuk tradisi, hukum, budaya dan iman suku Dayak Kanayatn. "Yang Maha Ada" telah dikenal dengan sebutan Yahweh dalam tradisi, budaya dan iman orang Israel.

Pribadi yang sama telah menyatakan diri-Nya kepada suku Dayak Kanayatn dengan tradisi, budaya, dan

43 Suhermanto Ja'far, "Panenteisme Dalam Pemikiran Teologi Metafisik Moh. Iqbal," Kalam 6, no. 2 (2017): 273. iman dalam konteks yang dimiliki mereka. Yahweh dan Jubata adalah sama.

\section{Konstruksi Kontekstualisasi Nama Jubata sebagai Yahweh}

Dari hasil perbandingan di atas, ditemukan bahwa yang menjadi pembeda antara Yahweh dan Jubata adalah konteks dan tradisi dimana mereka dikenal. Yahweh muncul dan dikenal di budaya Timur Tengah Kuno, secara khusus Israel. Yahweh telah menunjukkan kuasaNya, mengangkat Israel menjadi umatNya dan menjadi Allah Israel serta senantiasa memelihara Israel. budaya yang dipegang oleh Israel telah berperan dalam membentuk pola kultus mereka terhadap Yahweh.

Jika Israel menyembah Yahweh pada kemah suci, hal itu terjadi karena memang kondisi mereka yang nomaden; sedangkan Jubata muncul dalam konteks dan tradisi orang Dayak Kanayatn yang bercorak agraris, sehingga Jubata selalu dikaitkan dengan alam. Tidak heran jika orang Dayak Kanayatn melakukan ritual keagamaannya pada tempat khusus yang dianggap sebagai tempat sakral seperti gunung, ladang, pohon-pohon, sungai, persimpangan jalan dan tempat lainnya. Kehadiran-Nya dalam konteks yang berbeda membuat Ia dikenal dan 
disembah dengan cara pandang yang berbeda.

Menurut penulis, konteks bukanlah sebuah jarak yang tidak dapat dijembatani untuk menyebut Yahweh sebagai Jubata. Dengan kedinamisanNya, Yahweh juga dapat dilihat dari sosok Jubata. Gereja yang melayani suku Dayak Kanayatn harus mampu menjelaskan ketuhanan Yahweh dalam perpektif Alkitabiah - bukan saja telogi yang diproduksi gereja Barat - dan menerjemahkannya kedalam pemikiran kearifan lokal seperti makna dalam sebuah ritual, kesenian, cerita-cerita rakyat dan hal-hal yang dianggap sakral oleh suku Dayak Kanayatn.

Saran yang dapat dijadikan pedoman untuk melakukan kontekstualisasi Yahweh dalam pemahaman Jubata adalah memelajari pola pikir orang Dayak Kanayatn terhadap Jubata melalui hukum adat yang dipegang, ritual-ritual penting, hari-hari penting, mite yang berkembang didaerah itu, larangan dan anjuran yang berkembang di tengah masyarakat. Hal lain yang tidak kalah penting adalah harus senantiasa diingat adalah mendengar dengan seksama apa yang menjadi kebutuhan dan pergumulan aktual mereka; dari pada mengajar mereka. Hadirkanlah sosok Yahweh dari perspektif Alkitab yang diterjemahkan dalam pola pikir mereka terhadap Jubata yang terkandung dalam hal-hal yang dianggap penting seperti contoh di atas, sehingga Yahweh dan nilai-nilai-Nya dapat menjadi jawaban atas pergumulan aktual yang mereka hadapi.

Dalam model kontekstualisasi yang demikian, hal yang patut diterima oleh gereja adalah aturan-aturan adat yang berfungsi menertibkan keadaan sosial masyarakat. Selain itu ada nilainilai moral yang baik yang terkandung dalam mite dan filososfi yang berkembang di masyarakat yang harus dipahami gereja dengan tidak menganggapnya sebagai dongeng belaka. Gereja harus berperan aktif dalam tiaptiap kegiatan sosial masyarakat Dayak Kanayatn, baik itu gotong royong, maupun kegiatan ritual-ritual mereka. Semua ini harus dilakukan demi suksesnya kontekstualisasi Yahweh ke dalam pemahaman Jubata.

Adapun hal-hal yang harus ditinggalkan adalah kultur budaya Barat yang tidak relevan dengan kebutuhan aktual suku Dayak Kanayatn. Selain itu perlu kewaspadaan dalam melakukan bedah budaya suku Dayak Kanayatn agar tidak terjebak dalam dualisme yang menyembah kepada Jubata atau allahallah (hantu) kecil lain yang biasanya dijadikan penolong disaat mereka terdesak. 


\section{KESIMPULAN}

Secara Teologis, Yahweh dan Jubata memiliki sebuah paralel yang sepadan. Hal tersebut tentu bukan sebuah kebetulan terjadi, mengingat bahwa Yahweh dalam kedinamisan-Nya dan kedaulatan-Nya bebas menyatakan diri dalam berbagai cara kepada seluruh umat manusia. Hal itu secara khusus mendapat tempat dalam perhatian suku Dayak dalam memahami iman mereka kepada Jubata. Gereja yang melayani suku Dayak Kanayatn harus mampu menangkap penyataan umum yang dinyatakan oleh Yahweh bagi suku Dayak Kanayatn, kemudian menjelaskannya dalam terang injil melalui kebudayaan dan kebiasaan yang dapat dipahami dan dinikmati oleh mereka, tentunya dengan tidak meninggalkan kemurnian dan kesucian Injil. Dengan demikian, Injil akan sangat mudah mendapat tempat dan perhatian serta mampu memberi pengaruh yang dapat mentransformasi nilai-nilai dalam kebudayaan suku Dayak Kanayatn.

\section{DAFTAR PUSTAKA}

Barth, Christoph, and Marie-Claire Barth. Teologi Perjanjian Lama 1. Edited by Borozatulo Gea and

Chrisostomus Sihotang. 1st ed. Jakarta: BPK Gunung Mulia, 2008. Barth, Christoph, and Merie Claire Barth. Teologi Perjanjian Lama 2. Edited by Gabo Gea. 1st ed. Jakarta: BPK Gunung Mulia, 2010.

Clover, R. The Sacred Name. 3rd ed. USA: Qadesh La YAHWEH Press, 2002.

Darmadi, Hamid. "Dayak Asal-Usul Dan Penyebarannya Di Bumi Borneo." Sosial Horizon 3, no. 2 (2016): 322340.

Eichordt, Walther. Theology of The Old Testament. 2nd ed. London: SCM, 1993.

Geertz, Clifford. "The Interpretation Of Cultures (Basic Books Classics)" (1977).

Hartatik. Adat Dan Perubahan Budaya

Pada Masyarakat Suku Dayak

Kanayatn, 2016.

Heridawati. "Naik Dango: Ucapan

Syukur Dalam Menghormati Padi

Pada Suku Dayak Kanayatn 19851991," 2007. 
Ja'far, Suhermanto. "Panenteisme Dalam

Pemikiran Teologi Metafisik Moh.

Iqbal.” Kalam 6, no. 2 (2017): 273.

Kaiser, Walter C. Teologi Perjanjian

Lama. 3rd ed. Jakarta: BPK Gunung

Mulia, 2013.

Kettel, ed. Biblica Hebraica

Stuttgartensia. 1st ed. New York:

J.C. Hinrich, n.d.

Klapwijk, Jasper. Kabar Baik Dari

Perjanjian Lama. Jakarta: Yayasan

Komunikasi Bina Kasih/OMF,

2015.

Knight, George W. The Names Of God.

5th ed. Yogyakarta: Andi, 2015.

Kondoj, Brando V. "Mencari Jejak-Jejak

Autograf Perjanjian Lama Di Dalam

Septuaginta" (n.d.): 33-46.

Lumingkewas, Marthin Steven. El Dan

Yahweh Allah Israel. Yogyakarta:

Diandra Kreatif, n.d.

Mangililo, Ira Desiawanti. "Nama

Yahweh: Suatu Tinjauan Etimologis

Terhadap Arti Dan Penggunaan

Nama Yahweh Berdasarkan

Keluaran 3:14." Waskita, Jurnal

Studi Agama dan Masyarakat Vol.

III, No. 2, Nov. 2016: 161-176

(2016): 6 .

MARAGA, RAONIGEL TALU.

"Penyelesaian Sengketa

Kepemilikan Tanah Di Lingkungan

Masyarakat Adat Dayak Kanayatn,

Kecamatan Menyuke, Kabupaten
Landak, Provinsi Kalimantan

Barat." Universitas Diponegoro

Semarang. Universitas Diponegoro

Semarang, 2017.

Mawene, Mathinus Theodorus.

Perjanjian Lama Dan Teologi

Kontekstual. Jakarta: BPK Gunung

Mulia, 2017.

Munthe, Eben. "Implikasi Penggunaan

'El'Dan 'YHWH' Dalam

Kekristenan Masa Kini.” KURIOS

(Jurnal Teologi dan Pendidikan

Agama Kristen) 5, no. 1 (2019): 54-

73.

Niebuhr, Richard. Christ And Culture.

New York: Herper And Row

Publisher, 1951.

Noorsena, Bambang. The History of

Allah. 6th ed. Yogyakarta: Andi, 2010.

Panjaitan, Firman. "Membangun Teologi

Pertanian Melalui Pembacaan Lintas

Tekstual Injil Matius Dan

Kosmologi Jawa.” Bonafide: Jurnal

Teologi dan Pendidikan Kristen 1, no. 1 (2020): 44-64.

Rukin. Metode Penelitian Kualitatif. 1st

ed. Takalar: Yayasan Ahmar

Cendikia Indonesia, 2019.

Satria, Denny. "Penerapan Hukum Adat

Daya’ Kanayatn Dalam

Penyelesaian Kasus Hukum Pidana

Di Kabupaten Landak Dan Dasar

Pemikiran Pengaturannya Ke Dalam 
Peraturan Daerah,” n.d.

Sitohang, Samin H. Siapakah Nama Sang

Pencipta. Bandung: Yayasan Kalam

Hidup, 2003.

Son, Samuel Bagster And. The Analytical

Hebrew And Chaldee Lexicon.

London: Hendrickson Publisher, 1981.

Stompul, A.A, and Ulrich Beyer. Metode Penafsiran Alkitab. Edited by Staf

Redaksi BPK Gunung Mulia. 21st

ed. Jakarta: BPK Gunung Mulia, 2016.

Sujoko, Albert. Belajar Menjadi

Manusia. 5th ed. Yogyakarta:

Kanisius, 2012.

Superman, Superman. "Peristiwa

Mangkok Merah Di Kalimantan

Barat Tahun 1967.” Historia 5, no. 1

(2017): 1 .

Suwarno, P.J. Pancasila Budaya Bangsa

Indonesia. 9th ed. Yogyakarta:

Kanisius, 2009.

Towns, Elmer E. Nama-Nama Allah. 7th

ed. Yogyakarta: Andi, 2008.

Ukur, Fridolin. Tantang-Jawab Suku

Dayak. 1st ed. jakarta: Balai

Penerbit Kristen, 1971.

Ursula, Dwi Oktaviani. "Mantra Upacara

Ngabati' Pada Upacara Pertanian

Suku Dayak Kanayatn Di Dusun

Pakbuis Desa Banying Kecamatan

Sengah Temila Kabupaten Landak
Kalimantan Barat.” Vox Edukasi (2015).

Zed, Mestika. Metode Penelitian

Kepustakaan. 3rd ed. Jakarta:

Yayasan Pustaka Obor Indonesia, 2014.

Barth, Christoph, and Marie-Claire Barth. Teologi Perjanjian Lama 1. Edited by Borozatulo Gea and

Chrisostomus Sihotang. 1st ed. Jakarta: BPK Gunung Mulia, 2008.

Barth, Christoph, and Merie Claire Barth. Teologi Perjanjian Lama 2. Edited by Gabo Gea. 1st ed. Jakarta: BPK Gunung Mulia, 2010.

Clover, R. The Sacred Name. 3rd ed. USA: Qadesh La YAHWEH Press, 2002.

Darmadi, Hamid. "Dayak Asal-Usul Dan Penyebarannya Di Bumi Borneo." Sosial Horizon 3, no. 2 (2016): 322340.

Eichordt, Walther. Theology of The Old Testament. 2nd ed. London: SCM, 1993.

Geertz, Clifford. "The Interpretation Of Cultures (Basic Books Classics)" (1977).

Hartatik. Adat Dan Perubahan Budaya Pada Masyarakat Suku Dayak Kanayatn, 2016.

Heridawati. "Naik Dango: Ucapan 
Syukur Dalam Menghormati Padi

Pada Suku Dayak Kanayatn 19851991," 2007.

Ja'far, Suhermanto. "Panenteisme Dalam

Pemikiran Teologi Metafisik Moh.

Iqbal.” Kalam 6, no. 2 (2017): 273.

Kaiser, Walter C. Teologi Perjanjian

Lama. 3rd ed. Jakarta: BPK Gunung

Mulia, 2013.

Kettel, ed. Biblica Hebraica

Stuttgartensia. 1st ed. New York:

J.C. Hinrich, n.d.

Klapwijk, Jasper. Kabar Baik Dari

Perjanjian Lama. Jakarta: Yayasan

Komunikasi Bina Kasih/OMF, 2015.

Knight, George W. The Names Of God.

5th ed. Yogyakarta: Andi, 2015.

Kondoj, Brando V. "Mencari Jejak-Jejak

Autograf Perjanjian Lama Di Dalam

Septuaginta" (n.d.): 33-46.

Lumingkewas, Marthin Steven. El Dan

Yahweh Allah Israel. Yogyakarta:

Diandra Kreatif, n.d.

Mangililo, Ira Desiawanti. "Nama

Yahweh: Suatu Tinjauan Etimologis

Terhadap Arti Dan Penggunaan

Nama Yahweh Berdasarkan

Keluaran 3:14." Waskita, Jurnal

Studi Agama dan Masyarakat Vol.

III, No. 2, Nov. 2016: 161-176

(2016): 6 .

MARAGA, RAONIGEL TALU.

"Penyelesaian Sengketa
Kepemilikan Tanah Di Lingkungan

Masyarakat Adat Dayak Kanayatn,

Kecamatan Menyuke, Kabupaten

Landak, Provinsi Kalimantan

Barat." Universitas Diponegoro

Semarang. Universitas Diponegoro

Semarang, 2017.

Mawene, Mathinus Theodorus.

Perjanjian Lama Dan Teologi

Kontekstual. Jakarta: BPK Gunung

Mulia, 2017.

Munthe, Eben. "Implikasi Penggunaan

'El'Dan 'YHWH' Dalam

Kekristenan Masa Kini.” KURIOS

(Jurnal Teologi dan Pendidikan

Agama Kristen) 5, no. 1 (2019): 54-

73.

Niebuhr, Richard. Christ And Culture.

New York: Herper And Row

Publisher, 1951.

Noorsena, Bambang. The History of

Allah. 6th ed. Yogyakarta: Andi, 2010.

Panjaitan, Firman. "Membangun Teologi Pertanian Melalui Pembacaan Lintas Tekstual Injil Matius Dan

Kosmologi Jawa.” Bonafide: Jurnal Teologi dan Pendidikan Kristen 1, no. 1 (2020): 44-64.

Rukin. Metode Penelitian Kualitatif. 1st ed. Takalar: Yayasan Ahmar Cendikia Indonesia, 2019.

Satria, Denny. "Penerapan Hukum Adat Daya’ Kanayatn Dalam 
Penyelesaian Kasus Hukum Pidana

Di Kabupaten Landak Dan Dasar

Pemikiran Pengaturannya Ke Dalam

Peraturan Daerah," n.d.

Sitohang, Samin H. Siapakah Nama Sang

Pencipta. Bandung: Yayasan Kalam

Hidup, 2003.

Son, Samuel Bagster And. The Analytical

Hebrew And Chaldee Lexicon.

London: Hendrickson Publisher,

1981.

Stompul, A.A, and Ulrich Beyer. Metode

Penafsiran Alkitab. Edited by Staf

Redaksi BPK Gunung Mulia. 21st

ed. Jakarta: BPK Gunung Mulia,

2016.

Sujoko, Albert. Belajar Menjadi

Manusia. 5th ed. Yogyakarta:

Kanisius, 2012.

Superman, Superman. "Peristiwa

Mangkok Merah Di Kalimantan

Barat Tahun 1967." Historia 5, no. 1 (2017): 1.

Suwarno, P.J. Pancasila Budaya Bangsa

Indonesia. 9th ed. Yogyakarta:

Kanisius, 2009.

Towns, Elmer E. Nama-Nama Allah. 7th

ed. Yogyakarta: Andi, 2008.

Ukur, Fridolin. Tantang-Jawab Suku

Dayak. 1st ed. jakarta: Balai

Penerbit Kristen, 1971.

Ursula, Dwi Oktaviani. "Mantra Upacara

Ngabati' Pada Upacara Pertanian
Suku Dayak Kanayatn Di Dusun

Pakbuis Desa Banying Kecamatan

Sengah Temila Kabupaten Landak

Kalimantan Barat." Vox Edukasi

(2015).

Zed, Mestika. Metode Penelitian

Kepustakaan. 3rd ed. Jakarta:

Yayasan Pustaka Obor Indonesia, 2014. 
